\title{
Revealing Glycoproteins in the Secretome of MCF-7 Human Breast Cancer Cells
}

\author{
Aik-Aun Tan, ${ }^{1}$ Wai-Mei Phang, ${ }^{2}$ Subash C. B. Gopinath, ${ }^{3}$ Onn H. Hashim, \\ Lik Voon Kiew, ${ }^{5}$ and Yeng Chen ${ }^{2,6}$ \\ ${ }^{1}$ Institute for Research in Molecular Medicine (INFORMM), Universiti Sains Malaysia, 11800 Penang, Malaysia \\ ${ }^{2}$ Department of Oral Biology \& Biomedical Sciences, Faculty of Dentistry, University of Malaya, 50603 Kuala Lumpur, Malaysia \\ ${ }^{3}$ Institute of Nano Electronic Engineering (INEE) and School of Bioprocess Engineering, Universiti Malaysia Perlis, \\ 01000 Kangar, Perlis, Malaysia \\ ${ }^{4}$ Department of Molecular Medicine, Faculty of Medicine, University of Malaya, 50603 Kuala Lumpur, Malaysia \\ ${ }^{5}$ Department of Pharmacology, Faculty of Medicine, University of Malaya, 50603 Kuala Lumpur, Malaysia \\ ${ }^{6}$ Oral Cancer Research and Coordinating Centre, Faculty of Dentistry, University of Malaya, 50603 Kuala Lumpur, Malaysia
}

Correspondence should be addressed to Yeng Chen; chenyeng@um.edu.my

Received 13 April 2015; Accepted 7 June 2015

Academic Editor: Marko Pesu

Copyright (C) 2015 Aik-Aun Tan et al. This is an open access article distributed under the Creative Commons Attribution License, which permits unrestricted use, distribution, and reproduction in any medium, provided the original work is properly cited.

\begin{abstract}
Breast cancer is one of the major issues in the field of oncology, reported with a higher prevalence rate in women worldwide. In attempt to reveal the potential biomarkers for breast cancer, the findings of differentially glycosylated haptoglobin and osteonectin in previous study have drawn our attention towards glycoproteins of secretome from the MCF-7 cancer cell line. In the present study, further analyses were performed on the medium of MCF-7 cells by subjecting it to two-dimensional analyses followed by image analysis in contrast to the medium of human mammary epithelial cells (HMEpC) as a negative control. Carboxypeptidase A4 (CPA4), alpha-1-antitrypsin (AAT), haptoglobin (HP), and HSC70 were detected in the medium of MCF-7, while only CPA4 and osteonectin $(\mathrm{ON})$ were detected in HMEpC medium. In addition, CPA4 was detected as upregulated in the MCF-7 medium. Further analysis by lectin showed that CPA4, AAT, HP, and HSC70 were secreted as N-glycan in the medium of MCF-7, with HP also showing differentially $\mathrm{N}$-glycosylated isoforms. For the HMEpC, only CPA4 was detected as N-glycan. No O-glycan was detected in the medium of HMEpC but MCF-7 expressed O-glycosylated CPA4 and HSC70. All these revealed that glycoproteins could be used as glycan-based biomarkers for the prognosis of breast cancer.
\end{abstract}

\section{Introduction}

Breast cancer occurs predominantly in the female population. A few cases of breast cancer were reported in males, increasing the deaths reported worldwide. Breast cancer is a type of carcinoma formed in milk ducts and glands. If untreated, the cancer tissues will grow abnormally and spread to surrounding tissues. Different causes have been proposed for the development of breast cancer $[1,2]$. Of all the factors involved, older women and those with a family history of breast cancer have a higher chance of being affected by breast cancer. Apart from these factors, the involvement of noncoding RNA and micro-RNA in cancer progression has also been reported [3-5]. Gopinath et al. [4] have revealed that noncoding RNA resides in the vault particles of cancer cells responsible for multidrug resistance. Meanwhile, Isobe et al. [5] demonstrated the regulation of tumorigenicity in breast cancer stem cells by the miR-142 micro-RNA through the canonical WNT signaling pathway. For different reasons, breast cancer has accounted for over $25 \%$ of all cancers diagnosed and causes death in a significant proportion of cases [6-8]. Based on the statistical reports of the American Cancer Society, estimated 231,840 new invasive breast cancer cases are expected to be diagnosed among the female population in the US in 2015 and it is estimated that 40,290 deaths from the disease will be reported in the same period.

The higher incidence rate for breast cancer is mainly due to a failure to detect it in the early stages. Breast tomosynthesis, 3D imaging techniques, and digital mammography 
are the methods currently used to diagnose breast cancer. In addition, several other detection systems have also been proposed [9-13]. These analyses help to some extent in the stage-specific diagnosis of breast cancer; however, these detection systems are hindered by the higher expectation of additional biomarkers expressed during the cancer developing stages [10]. The present study analyzes the excretion of proteins during the growth of MCF-7 cancer cells compared to normal HMEpC cells. Excreted proteins were evaluated with the assistance of proteomics using two-dimensional analyses followed by imaging analyses. Moreover, the focus of this study is the analyses of glycoproteins, as these proteins are involved in the posttranslational modifications which could contribute to tumorigenesis $[14,15]$. Hence, these observations might lead to the discovery of biomarkers for early diagnosis of breast cancer.

\section{Materials and Methods}

2.1. Cell Culture. Human breast cancer cell line MCF-7 (catalogue number HTB-22) and human mammary epithelial cell HMEpC (catalogue number 830K-05a) were purchased from ATCC and Cell Applications, respectively. MCF-7 cells were cultured in Dulbecco's modified Eagle's medium (DMEM) containing 10\% fetal bovine serum (Invitrogen, CA, USA). For HMEpC, cells were cultured in Mammary Epithelial Cell Growth Medium (Cell Applications, CA, USA) as recommended by a manufacturer. Both cell lines were maintained in a humidified atmosphere of $5 \% \mathrm{CO}_{2}$ at $37^{\circ} \mathrm{C}$. The cells were kept separately and handled individually to prevent crosscontamination. Cell growth was monitored and maintained at logarithmic growth phase.

2.2. Sampling of Growth Medium. The cells were cultured in $75 \mathrm{~cm}^{2}$ flasks until $80 \%$ confluence and the used growth media were then removed. The cells were washed three times with phosphate buffered saline (PBS) (Invitrogen), $\mathrm{pH} 7.4$, and incubated for another $24 \mathrm{~h}$ in serum-free media. Serumfree media were harvested, centrifuged at $2000 \times \mathrm{g}$ to remove cell debris, and kept in $-80^{\circ} \mathrm{C}$ until further processing. Before being subjected to two-dimensional electrophoresis (2DE), the harvested media were concentrated 100-fold using Vivaspin concentrators (10,000 molecular weight cut-off; Sartorius) and impurities were removed with 2D Clean-Up Kit (GE Healthcare Bio-Sciences, Uppsala, Sweden).

2.3. Two-Dimensional Electrophoresis (2D-E) and Silver Staining. 2D-E was carried out as previously described [16]. Immobilized $\mathrm{pH}$ gradient (IPG) strips (GE Healthcare BioSciences) with length of $13 \mathrm{~cm}$ and immobilized $\mathrm{pH}$ gradients of 3-10 and 4-7 were used. The broad range $\mathrm{pH} 3-10$ IPG strip was used to view the overall protein distribution of the sample, while the $\mathrm{pH} 4-7$ IPG strip was used to produce a higher resolution of the protein profile. Concentrated protein samples from growth media were rehydrated with IPG strips in a rehydration buffer ( $8 \mathrm{M}$ urea, $2 \mathrm{M}$ thiourea, $20 \mathrm{mM}$ dithiothreitol, 4\% CHAPS, and $0.5 \%$ pharmalyte) and incubated overnight. The strips were then subjected to isoelectric focusing (IEF) using the Ettan IPGphor II IEF system (GE Healthcare Bio-Sciences). The strips were subsequently equilibrated and applied onto the $8-18 \%$ gradient gels for second dimensional separation. The SDS-PAGE was performed using the Hoefer SE 600 Ruby system (GE Healthcare BioSciences). The 2D-E gels were silver stained according to Heukeshoven and Dernick [17]. For mass spectrometry, gels were silver stained as described by Shevchenko et al. [18] with modification.

\subsection{Con A (Concanavalin A) Affinity Chromatography for} $N$-Linked Glycosylation Analysis. Ten milliliters of harvested medium was added to $2 \mathrm{~mL}$ of Con A Sepharose (GE Healthcare Bio-Sciences, Uppsala, Sweden) and gently shaken overnight at $4^{\circ} \mathrm{C}$. The mixture was subsequently loaded into a $0.8 \times 4 \mathrm{~cm}$ Poly-Prep column (BioRad Laboratories, Hercules, CA, USA) and equilibrated with an equilibration buffer (20 mM Tris- $\mathrm{HCl}, 0.5 \mathrm{M} \mathrm{NaCl}, \mathrm{pH} 7.4)$. The column was washed with $50 \mathrm{~mL}$ of equilibration buffer to remove unbound proteins (nonglycosylated and O-glycosylated proteins); and bound $\mathrm{N}$-glycoproteins were eluted with $0.3 \mathrm{M}$ methyl- $\alpha$-D-glucopyranoside. Chromatographic process was monitored at the absorbance of $280 \mathrm{~nm}$. The eluted fractions were pooled and concentrated 100-fold using Vivaspin concentrators (10,000 molecular weight cut-off; Sartorius). Concentrated eluate was further desalted using 2D CleanUp Kit (GE Healthcare Bio-Sciences, Uppsala, Sweden) and subjected to $2 \mathrm{D}$-E.

\subsection{Western Blotting and Champedak Galactose Binding} Lectin Detection for O-Linked Glycosylation Analysis. Proteins in 2D-E growth media gel were electroblotted onto a nitrocellulose membrane $(0.45 \mu \mathrm{m})$ using Multiphor II NovaBlot Kit (GE Healthcare Bio-Sciences, Uppsala, Sweden). The blotted membrane was then incubated with 5\% skimmed milk in Tween TRIS-buffered saline (TTBS) for 1 hour at room temperature to block nonspecific protein binding sites. The membrane was then washed 3 times with TTBS, 15 min each. Detection of transferred O-glycosylated proteins was performed by incubation with champedak galactose binding lectin conjugated to horseradish peroxidase at a concentration of approximately $1 \mu \mathrm{g} / \mathrm{mL}$, overnight at $4^{\circ} \mathrm{C}$. The purity and specificity of this lectin to interact with O-glycosylated proteins were described previously [19]. After the incubation, the membrane was washed twice and developed using freshly prepared 3,3' -diaminobenzidine (Dako, Glostrup, Denmark) in $50 \mathrm{~mL}$ of TRIS-buffered saline mixed with $50 \mu \mathrm{L}$ of $\mathrm{H}_{2} \mathrm{O}_{2}$. Reaction was terminated by washing the membrane twice with deionized distilled water, $5 \mathrm{~min}$ each. The developed membrane was air-dried and scanned with GS-710 Imaging Densitometer (Bio-Rad).

2.6. Image Analysis. GS-710 Imaging Densitometer (Bio$\mathrm{Rad}$ ) and PDQuest software (version 4.7.0, Bio-Rad) were used to capture, store, and analyze protein spots on $2 \mathrm{D}-\mathrm{E}$ gels and lectin blots. PDQuest software matched the identical spots in a series of gels and normalized the gels to compensate 
for any variations between gels, especially those caused by varying experimental conditions. The analysis was normalized by total density in gel, which accounts for the raw quantity of each spot in a gel, divided by the total intensity value of all the pixels in the image. The normalized spot quantity was expressed as percentages of volume contributions (vol\%) to facilitate the data compilation. Data was checked manually to eliminate possible error in matching pairs.

2.7. Statistical Analysis. All protein concentration values were presented as mean of percentage volume (\% volume) \pm SE. The Student's $t$-test was used to analyze the statistical differences between normal and cancer samples and to examine the correlation between the variables. A $p$ value of less than 0.05 $(p<0.05)$ was considered statistically significant.

2.8. Protein Identification with Mass Spectrometry (MS). The resolved protein spots of interest were excised and subjected to in-gel digestion using ProteoExtract All-in-One Trypsin Digestion Kit (Merck, USA). Digested peptides were further purified and concentrated using ZipTip $\mathrm{C}_{18}$ (Millipore, MA, USA). Mass spectrometric analysis was performed at the Proteomic Centre, Department of Biological Sciences, National University of Singapore. Digested peptide was mixed with $1 \mu \mathrm{L}$ of CHCA $(5 \mathrm{mg} / \mathrm{mL}$ of alpha-cyano-4-hydroxycinamic acid in $0.1 \%$ trifluoroacetic acid and $50 \%$ acetonitrile in deionized distilled water) and applied to a Matrix-Assisted Laser Desorption/Ionization (MALDI) target plate. The mixture was allowed to dry under ambient temperature to ensure optimum crystal growth. The target plate with dried mixture was then inserted into a mass spectrometer for analysis. The peptide mass spectra were obtained by using the ABI 4800 Proteomics Analyzer MALDI-TOF/TOF Mass Spectrometer (Applied Biosystems, Framingham, MA, USA).

For protein identification, mass spectra obtained were searched for in the National Center for Biotechnology Information nonredundant (NCBInr) protein database using the MASCOT search engine (version 2.1; Matrix Science, London, UK). Searches were performed with fixed modification on carbamidomethylation of cysteines and variable modification of methionine oxidation. The following parameters were used in the MASCOT peptide mass fingerprint search: (i) enzyme: trypsin with one missed cleavage allowed, (ii) species: Homo sapiens, (iii) mass value: monoisotopic, (iv) peptide mass tolerance: $\pm 0.1 \mathrm{Da}$, and (v) peptide charge state: $1+$. The same parameters were used in the MASCOT ion search, except for peptide mass tolerance and fragment mass tolerance which were set at $100 \mathrm{ppm}$ and $0.2 \mathrm{Da}$, respectively. A search score of more than 50 indicated identities or extensive homology $(p<0.05)$.

\section{Results and Discussion}

Most of the aberrantly expressed proteins are acute phase proteins, which altered their expression level in response to the inflammation associated with the development of cancer [20]. Cancer has been reported to cause unusual changes in the protein expression of cells, either by increasing or reducing the expression level or altering the posttranslational modification of the proteins. Glycosylation is a type of extensive posttranslational modification which has a significant involvement in the functional alteration of proteins and, as reported previously, the aberrant glycosylation in the cancerous cells [21-23]. Based on our preliminary study on the glycosylation of proteins from human breast cancer cells, we encountered the aberrant expression of osteonectin and haptoglobin [15]. In the present study, we have expanded this further with the similar analysis and discovered the additional candidates which undergo differential glycosylation, through comparison of the secretome from MCF-7 cells with human mammary epithelial cells (HMEpC). The MCF-7 cell line is of luminal epithelial origin and is often used as a model for estrogen receptor-positive tumors, while HMEpC are normal epithelial cells derived from normal adult mammary glands.

\subsection{Typical Protein Profiles of MCF-7 and HMEpC Media.} Silver-stained 2D-E gels of HMEpC and MCF7 growth media were scanned using GS-710 Imaging Densitometer and analyzed using PDQuest 2D gel analysis software. Interestingly, the typical protein profile of MCF-7 medium differed considerably from the representative profile of HMEpC medium, with only some spots matched between them. Comparative analysis on the gel images revealed several differentially regulated proteins in both MCF7 and HMEpC media. A total of 5 distinctive protein spots were detected, 3 spots were exclusively expressed in MCF7 cells, one was in the HMEpC cells, and the other one was found in both MCF7 and HMEpC. These protein spots were further subjected to mass spectrometric analysis for protein identification.

Identification of protein spots of interest was performed by using Proteomics Analyzer MALDI-TOF/TOF Mass Spectrometer. The mass spectra obtained were searched for in the NCBInr protein database using the MASCOT search engine. The mass spectra of all digested samples are shown in Supplementary Figure 1 (in Supplementary Material available online at http://dx.doi.org/10.1155/2015/453289). A search score of more than 50 , which indicates extensive homology, was obtained for the five distinctive spots (Table 1). The proteins detected in the MCF-7 medium were identified as carboxypeptidase A4 (CPA4), alpha-1-antitrypsin (AAT), haptoglobin (HP), and HSC-70 (HSC70), whereas proteins found in the HMEpC medium were identified as carboxypeptidase A4 (CPA4) and osteonectin (ON). Protein profile analysis using PDQuest 2D gel analysis software revealed that there is a significantly higher expression of CPA4 in the MCF7 cell line (increased by a factor of 3.41, $p<0.05$ ), compared to HMEpC.

3.2. Posttranslational Modification Study. Analyses of growth media protein profiles were extended to include posttranslational modification studies. The protein profiles were generated by detection with Concanavalin A (Con A) and HRPconjugated champedak galactose binding (CGB) lectin. phy. Lectin Con A has high affinity towards alpha mannose, 
TABLE 1: Mass spectrometric identification of protein spots from MCF-7 and HMEpC growth media using MASCOT search engine and NCBI database.

\begin{tabular}{|c|c|c|c|c|c|c|}
\hline Spot name & Protein name & $\begin{array}{c}\text { Mascot accession } \\
\text { number }\end{array}$ & Theoretical pI & $\begin{array}{l}\text { Theoretical } \\
\text { mass (Da) }\end{array}$ & $\begin{array}{c}\text { Number of } \\
\text { peaks matched }\end{array}$ & Search score \\
\hline CPA4 & $\begin{array}{l}\text { Carboxypeptidase A4 } \\
\text { isoform } 2 \text { preproprotein }\end{array}$ & gi|254540196 & 8.49 & 43771 & 5 & 192 \\
\hline AAT & Alpha-1-antitrypsin & gi|177827 & 5.42 & 46787 & 2 & 85 \\
\hline HP & Haptoglobin & gi|223976 & 6.23 & 42344 & 2 & 70 \\
\hline HSC70 & $\begin{array}{c}\text { Chain A, crystal structure } \\
\text { of Hsc70 BAG1 in complex } \\
\text { with ATP }\end{array}$ & gi|225698069 & 6.38 & 42120 & 3 & 178 \\
\hline $\mathrm{ON}$ & Osteonectin & gi|338325 & 4.70 & 35260 & 1 & 81 \\
\hline
\end{tabular}

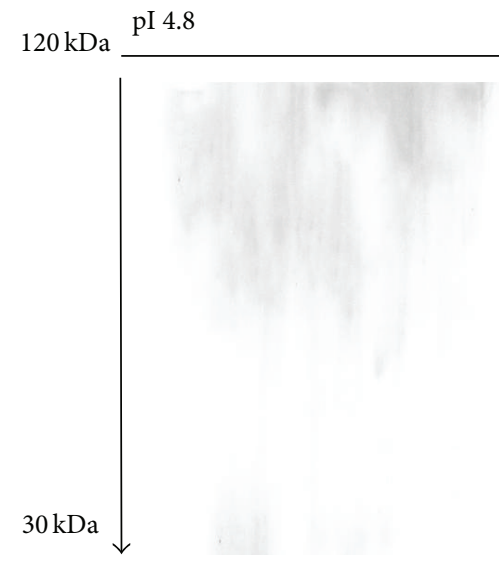

(a)

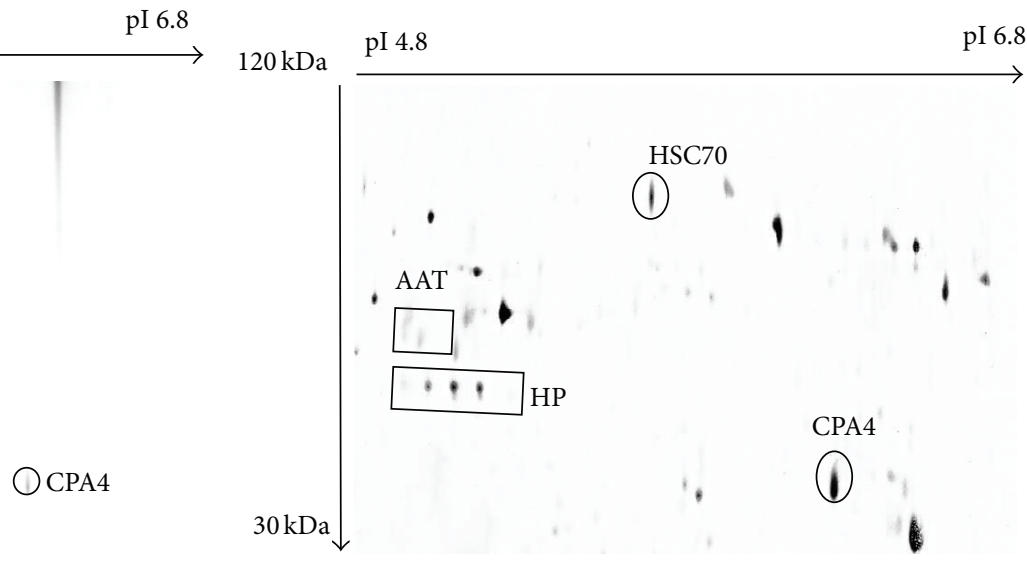

(b)

FIGURE 1: N-linked glycoproteins profile of (a) HMEpC growth medium, and (b) MCF-7 growth medium. Media of both HMEpC and MCF-7 cells were subjected to Con A chromatography and 2D-E. CPA4 was detected as N-glycoprotein in HMEpC medium, while N-glycosylated CPA4, AAT, HP, and HSC70 were detected in MCF7 medium.

and it is thus frequently used to purify and enrich N-linked glycoproteins $[24,25]$. The combination of lectin with $2 \mathrm{D}-\mathrm{E}$ analysis allowed screening for possible structural aberration in oligosaccharide moieties of secreted proteins. When MCF7 and HMEpC media were subjected to Con A coupled with $2 \mathrm{D}$-E analysis, different profiles consisting of only Nglycoproteins were obtained. The glycoprotein detected in the HMEpC N-glycoprotein profile was only CPA4 (Figure 1(a)). In contrast, N-glycoproteins detected in the MCF-7 medium included CPA4, AAT, HP, and HSC70 (Figure 1(b)). As previously reported [15], image analysis on the $\mathrm{N}$-glycoprotein profile of the MCF-7 medium indicated that one of the HP isoforms was absent, when compared to the total growth medium profile.

3.4. Detection of O-Glycoprotein Using CGB Lectin. For Oglycoprotein analyses, harvested growth media were subjected to 2D-E, blotted, and then developed with HRPconjugated CGB lectin. Distinctly different profiles were obtained when 2D-E separated growth media of MCF-7 and HMEpC were exposed to HRP-conjugated CGB lectin. For HMEpC, no O-glycoproteins were detected in the growth

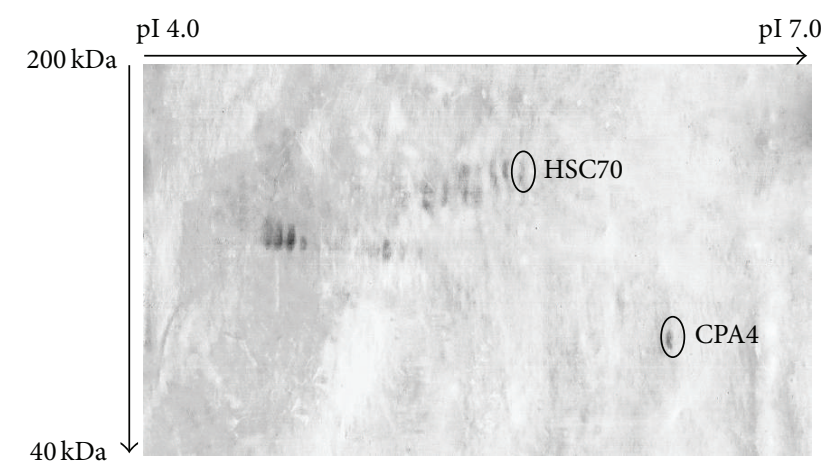

FIGURE 2: Typical representative of O-glycoprotein profile of MCF-7 growth medium. Harvested growth media were subjected to $2 \mathrm{D}-\mathrm{E}$, blotted, and then developed with HRP-conjugated CGB lectin. Protein spots of HSC70 and CPA4 were detected. No O-glycoproteins were detected in HMEpC growth medium (not shown).

medium. But, for MCF-7, O-glycosylated CPA4 and HSC70 were detected, as shown in Figure 2. 


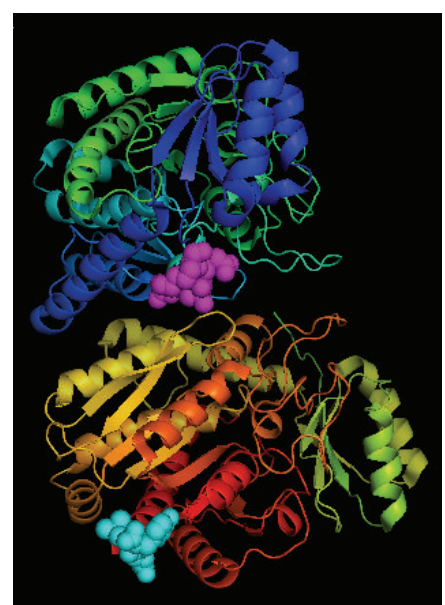

(a)

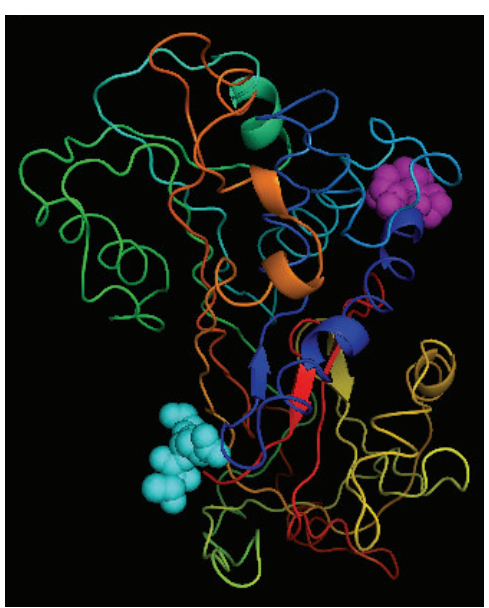

(b)

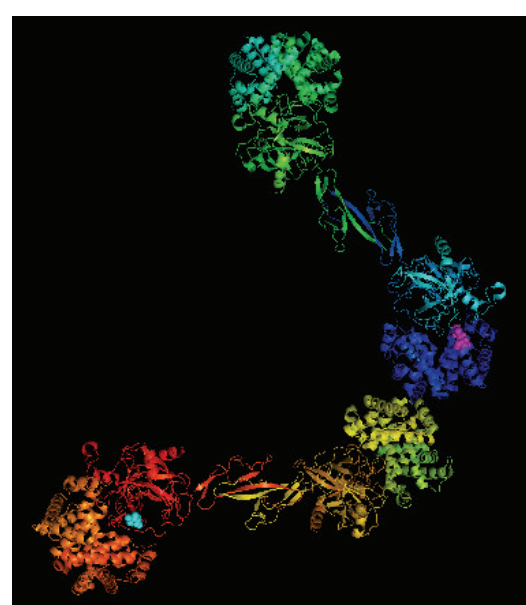

(c)

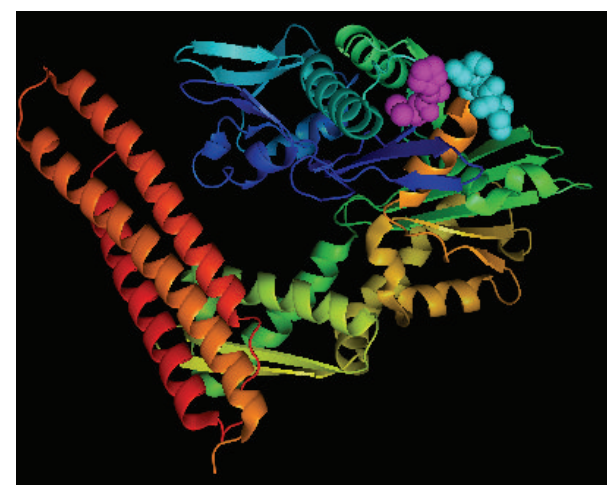

(d)

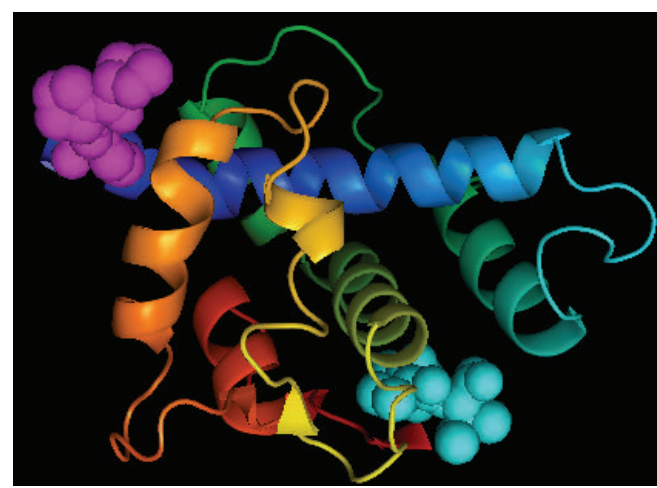

(e)

FIGURE 3: Three-dimensional representative of (a) carboxypeptidase A4 (PDB code: 2BOA), (b) alpha-1-antitrypsin (PDB code: 1KCT), (c) haptoglobin (PDB code: 4F4O), (d) HSC-70 (PDB code: 3FZF), and (e) osteonectin (PDB code: 1SRA). N and C terminals are shown with magenta and cyan colors, respectively.

3.5. Functional Aspects of the Identified Biomarkers. With the above studies, secreted proteins from MCF-7 and HMEpC cells were comparatively analyzed with proteomic approaches involving 2D-E and glycan-binding lectin. CPA4, AAT, HP, and HSC-70 were detected in the MCF-7 medium, where AAT, HP, and HSC70 were uniquely expressed. ON was only found in HMEpC cells. Aberrantly expressed proteins in in vitro study of human breast cancer cell lines have different structures and functions in relation to breast cancer. The three-dimensional structures of these identified biomarkers are well studied and readily available in the protein database (Figure 3).

3.6. Carboxypeptidase A4 (CPA4). CPA4 is a secreted exopeptidase that catalyzes the release of carboxyterminal amino acids. Although little is known about this enzyme, it is thought to participate in the histone hyperacetylation pathway during differentiation of prostate epithelial cancer cells [26]. Additionally, it was demonstrated that the gene for CPA4 is imprinted and may contribute to prostate cancer aggressiveness [27]. So far, no study has associated CPA4 expression with breast cancer. Our results demonstrated that
CPA4 is secreted at a higher level by MCF-7 cells in comparison to HMEpC, suggesting its role in breast cancer progression. Upon analysis of $\mathrm{N}$-glycoprotein profiles, CPA4 was detected in media from both MCF-7 and HMEpC cells. This finding is in accordance with a study by Pallarès et al. [28], which demonstrated that CPA4 is N-glycosylated at Asn-148 $\mathrm{N} \delta 2$. However, CPA4 was also detected as an O-glycosylated protein in MCF-7 media but not in HMEpC media. Therefore, our data indicate that CPA4 is aberrantly $\mathrm{O}$-glycosylated in MCF-7 cells, and this alteration may affect its function and/or structure in a manner that facilitates tumorigenesis.

3.7. Alpha-1-Antitrypsin (AAT). AAT is also known as alpha1 protease inhibitor, a $52-\mathrm{kD}$ a protease inhibitor belonging to the serpin family [29] that functions as an inhibitor of caspase activation and apoptosis. Notably, studies have already identified increased levels of AAT in the serum of breast cancer patients, suggesting its association with tumor advancement [30]. In addition, Yavelow et al. [31] have also reported the expression of AAT in MCF-7 cells. Therefore, our findings confirm this correlation of AAT with breast cancer. AAT was known to be a secreted N-glycosylated protein [32], and this 
is compatible with our observation of N-glycosylated AAT in the medium of MCF7 cells. Changes in N-linked glycosylation during the development of cancer have been correlated with tumor progression in human breast cancer [33].

3.8. Haptoglobin (HP). In parallel with our previous study [15], only the $\beta$-subunit of HP was studied in this investigation. Previous reports have associated the expression of HP with ovarian, breast, lung, and pancreatic cancers. Moreover, changes in oligosaccharide structures of HP variants may have contributed to tumorigenesis [34-38]. According to Chen et al. [16], the level of a secreted protein should be equivalent to its glycosylated forms. However, our findings demonstrated that HP isoforms secreted by MCF-7 cells were less N-glycosylated. Fucosylation of HP has been observed in pancreatic, breast, and ovarian cancer [38, 39]. Thus, HP may undergo differential glycosylation in associated cancer progression.

3.9. HSC70. HSC70 is a chaperone that facilitates proper polypeptide folding [40]. It also functions as an ATPase in the dissociation of clathrin-coated vesicles during transportation of membrane components through the cell [41]. Therefore, HSC70 is reported to be either a cytoplasmic or cell membrane-associated protein [42]. Here, we have detected extracellular HSC70 of MCF-7 cells. Although this finding could be a consequence of cell lysis or death, which is always possible in cell cultures, recent studies by Evdokimovskaya et al. [43] and Nirdé et al. [44] have supported the idea that HSC70 is actively secreted by various cell lines. So far, the mechanism and function of HSC70 secretion remain unknown. Nevertheless, our findings indicated that HSC70 is an $\mathrm{N}$ - and $\mathrm{O}$-glycosylated protein, and this information could help to elucidate the mechanism by which it is secreted. We postulate that glycosylation could even serve as a signal for HSC70 secretion.

3.10. Osteonectin $(\mathrm{ON})$. ON is a secreted glycoprotein responsible for cell adhesion, proliferation, migration, and tissue remodeling [45]. Underexpression of $\mathrm{ON}$ has been associated with tumorigenesis in human ovarian cancer [46] and poor prognosis in breast cancer patients [47]. Our findings showed that $\mathrm{ON}$ was secreted in the medium of HMEpC but not in MCF-7. ON was neither detected in N-glycoprotein nor $\mathrm{O}$-glycoprotein profiles of $\mathrm{HMEpC}$, even though a previous study has reported that it is an $\mathrm{N}$-glycoprotein [48]. These findings suggested that $\mathrm{ON}$ might be expressed in nonglycosylated form as $\mathrm{N}$-glycosylation sequons of glycoproteins are often not glycosylated under normal circumstances [49].

\section{Conclusions}

In this study, we have identified differentially expressed and glycosylated proteins in the secretions of human breast cancer cell line MCF-7. We employed a proteomics approach by using 2D-E coupled with lectin-base analysis to identify aberrantly expressed $\mathrm{N}$ - and $\mathrm{O}$-glycoproteins in the secretions from MCF-7 and HMEpC cells. Our analysis revealed that
CPA4, AAT, HP, and HSC70 were detected in the secretion of the MCF-7 cell line and AAT, HP, and HSC70 were uniquely expressed. However, only CPA4 and $\mathrm{ON}$ were detected in the HMEpC medium. Image analysis revealed that CPA4 was significantly expressed in the MCF-7 medium compared to HMEpC. Further analysis by lectin showed that CPA4, AAT, HP, and HSC70 were detected as $\mathrm{N}$-glycoproteins in the media of MCF-7, with HP showing differentially glycosylated isoforms. CPA4 was also detected as $\mathrm{N}$-glycoprotein in the media of HMEpC. On the other hand, the MCF-7 variants of CPA4 and HSC70 were detected as O-glycoproteins, but no $\mathrm{O}$-glycan was detected in HMEpC. HSC70 was detected as $\mathrm{N}$ - and $\mathrm{O}$-glycoprotein in the lectin analysis. These findings suggest that glycol-biomarkers could be used for human breast cancer screening and molecular targets for drug development.

\section{Conflict of Interests}

The authors have declared no conflict of interests.

\section{Acknowledgments}

This work was funded by University of Malaya Research Grants (UMRG) RG454-12HTM and University of Malaya (UM) High Impact Research (HIR) MoE Grants UM.C/ 625/1/HIR/MOE/DENT/09 and UM.C/625/1/HIR/MOHE/ $\mathrm{MED} / 16 / 5$ from the Ministry of Education Malaysia.

\section{References}

[1] P. D. Darbre, A. Aljarrah, W. R. Miller, N. G. Coldham, M. J. Sauer, and G. S. Pope, "Concentrations of parabens in human breast tumours," Journal of Applied Toxicology, vol. 24, no. 1, pp. 5-13, 2004.

[2] S. Thongprakaisang, A. Thiantanawat, N. Rangkadilok, T. Suriyo, and J. Satayavivad, "Glyphosate induces human breast cancer cells growth via estrogen receptors," Food and Chemical Toxicology, vol. 59, pp. 129-136, 2013.

[3] S. C. B. Gopinath, A. Matsugami, M. Katahira, and P. K. R. Kumar, "Human vault-associated non-coding RNAs bind to mitoxantrone, a chemotherapeutic compound," Nucleic Acids Research, vol. 33, no. 15, pp. 4874-4881, 2005.

[4] S. C. B. Gopinath, R. Wadhwa, and P. K. R. Kumar, "Expression of noncoding vault RNA in human malignant cells and its importance in mitoxantrone resistance," Molecular Cancer Research, vol. 8, no. 11, pp. 1536-1546, 2010.

[5] T. Isobe, S. Hisamori, D. J. Hogan et al., "miR-142 regulates the tumorigenicity of human breast cancer stem cells through the canonical WNT signaling pathway," eLife, vol. 3, Article ID e01977, 2014.

[6] A. J. Sasco, R. Kaaks, and R. E. Little, "Breast cancer: occurrence, risk factors and hormone metabolism," Expert Review of Anticancer Therapy, vol. 3, no. 4, pp. 546-562, 2003.

[7] J. Ferlay, H.-R. Shin, F. Bray, D. Forman, C. Mathers, and D. M. Parkin, "Estimates of worldwide burden of cancer in 2008: GLOBOCAN 2008," International Journal of Cancer, vol. 127, no. 12, pp. 2893-2917, 2010.

[8] R. Siegel, J. Ma, Z. Zou, and A. Jemal, "Cancer statistics, 2014," CA: A Cancer Journal for Clinicians, vol. 64, no. 1, pp. 9-29, 2014. 
[9] S. Kukreti, A. Cerussi, B. Tromberg, and E. Gratton, "Intrinsic near-infrared spectroscopic markers of breast tumors," Disease Markers, vol. 25, no. 6, pp. 281-290, 2008.

[10] H. J. Hathaway, K. S. Butler, N. L. Adolphi et al., "Detection of breast cancer cells using targeted magnetic nanoparticles and ultra-sensitive magnetic field sensors," Breast Cancer Research, vol. 13, no. 5, article R108, 2011.

[11] C. V. Nguyen and R. F. Saraf, "Tactile imaging of an imbedded palpable structure for breast cancer screening," ACS Applied Materials \& Interfaces, vol. 6, no. 18, pp. 16368-16374, 2014.

[12] Z. Tehrani, G. Burwell, M. A. Azmi et al., "Generic epitaxial graphene biosensors for ultrasensitive detection of cancer risk biomarker," 2D Materials, vol. 1, no. 2, Article ID 025004, 2014.

[13] J. Musayev, C. Altiner, Y. Adiguzel, H. Kulah, S. Eminoglu, and T. Akin, "Capturing and detection of MCF-7 breast cancer cells with a CMOS image sensor," Sensors and Actuators A: Physical, vol. 215, pp. 105-114, 2014.

[14] A. Varki, "Biological roles of oligosaccharides: all of the theories are correct," Glycobiology, vol. 3, no. 2, pp. 97-130, 1993.

[15] A. A. Tan, A. K. Mu, L. V. Kiew, and Y. Chen, "Comparative secretomic and $\mathrm{N}$-glycoproteomic profiling in human MCF-7 breast cancer and HMEpC normal epithelial cell lines using a gel-based strategy," Cancer Cell International, vol. 14, no. 1, article 120, 2014.

[16] R. Chen, Y. Tan, M. Wang et al., "Development of glycoprotein capture-based label-free method for the high-throughput screening of differential glycoproteins in hepatocellular carcinoma," Molecular \& Cellular Proteomics, vol. 10, no. 7, Article ID M110.006445, 2011.

[17] J. Heukeshoven and R. Dernick, "Simplified method for silver staining of proteins in polyacrylamide gels and the mechanism of silver staining," Electrophoresis, vol. 6, no. 3, pp. 103-112, 1985.

[18] A. Shevchenko, M. Wilm, O. Vorm, and M. Mann, "Mass spectrometric sequencing of proteins from silver-stained polyacrylamide gels," Analytical Chemistry, vol. 68, no. 5, pp. 850858, 1996.

[19] M. Abdul Rahman, S. Anuar Karsani, I. Othman, P. Shafinaz Abdul Rahman, and O. Haji Hashim, "Galactose-binding lectin from the seeds of champedak (Artocarpus integer): sequences of its subunits and interactions with human serum O-glycosylated glycoproteins," Biochemical and Biophysical Research Communications, vol. 295, no. 4, pp. 1007-1013, 2002.

[20] E. Gruys, M. J. M. Toussaint, T. A. Niewold, and S. J. Koopmans, "Review: acute phase reaction and acute phase proteins," Journal of Zhejiang University SCIENCE B, vol. 6, no. 11, pp. 1045-1056, 2005.

[21] S. A. Brooks, T. M. Carter, L. Royle et al., "Altered glycosylation of proteins in cancer: what is the potential for new anti-tumour strategies," Anti-Cancer Agents in Medicinal Chemistry, vol. 8, no. 1, pp. 2-21, 2008.

[22] F. M. Tuccillo, A. de Laurentiis, C. Palmieri et al., "Aberrant glycosylation as biomarker for cancer: focus on CD43," BioMed Research International, vol. 2014, Article ID 742831, 13 pages, 2014.

[23] M. N. Christiansen, J. Chik, L. Lee, M. Anugraham, J. L. Abrahams, and N. H. Packer, "Cell surface protein glycosylation in cancer," Proteomics, vol. 14, no. 4-5, pp. 525-546, 2014.

[24] M. Saleemuddin and Q. Husain, "Concanavalin A: a useful ligand for glycoenzyme immobilization-a review," Enzyme and Microbial Technology, vol. 13, no. 4, pp. 290-295, 1991.
[25] P. S. Abdul-Rahman, B.-K. Lim, and O. H. Hashim, "Expression of high-abundance proteins in sera patients with endometrial and cervical cancers: analysis using 2-DE with silver staining and lectin detection methods," Electrophoresis, vol. 28, no. 12, pp. 1989-1996, 2007.

[26] H. Huang, C. P. Reed, J. S. Zhang, V. Shridhar, L. Wang, and D. I. Smith, "Carboxypeptidase A3 (CPA3): a novel gene highly induced by histone deacetylase inhibitors during differentiation of prostate epithelial cancer cells," Cancer Research, vol. 59, no. 12, pp. 2981-2988, 1999.

[27] T. Kayashima, K. Yamasaki, T. Yamada et al., "The novel imprinted carboxypeptidase A4 gene (CPA4) in the 7q32 imprinting domain," Human Genetics, vol. 112, no. 3, pp. 220-226, 2003.

[28] I. Pallarès, R. Bonet, R. García-Castellanos et al., "Structure of human carboxypeptidase A4 with its endogenous protein inhibitor, latexin," Proceedings of the National Academy of Sciences of the United States of America, vol. 102, no. 11, pp. 39783983, 2005.

[29] P. G. W. Gettins, "Serpin structure, mechanism, and function," Chemical Reviews, vol. 102, no. 12, pp. 4751-4804, 2002.

[30] V. P. Demidov, R. I. Iakubovskaia, T. A. Karmakova et al., "alpha 1-proteinase inhibitor in breast cancer," Voprosy Onkologii, vol. 36, no. 1, pp. 23-29, 1990.

[31] J. Yavelow, A. Tuccillo, S. S. Kadner, J. Katz, and T. H. Finlay, “ $\alpha 1-$ Antitrypsin blocks the release of transforming growth factor- $\alpha$ from MCF-7 human breast cancer cells," The Journal of Clinical Endocrinology \& Metabolism, vol. 82, no. 3, pp. 745-752, 1997.

[32] V. Blanchard, X. Liu, S. Eigel et al., "N-glycosylation and biological activity of recombinant human alphal-antitrypsin expressed in a novel human neuronal cell line," Biotechnology and Bioengineering, vol. 108, no. 9, pp. 2118-2128, 2011.

[33] M. A. Comunale, M. Lowman, R. E. Long et al., "Proteomic analysis of serum associated fucosylated glycoproteins in the development of primary hepatocellular carcinoma," Journal of Proteome Research, vol. 5, no. 2, pp. 308-315, 2006.

[34] S.-K. Oh, D. L. Very, J. Walker, S. Raam, and S.-T. Ju, “An analogy between fetal haptoglobin and a potent immunosuppressant in cancer," Cancer Research, vol. 47, no. 19, pp. 5120-5126, 1987.

[35] F. P. Kuhajda, A. I. Katumuluwa, and G. P. Pasternack, "Expression of haptoglobin-related protein and its potential role as a tumor antigen," Proceedings of the National Academy of Sciences of the United States of America, vol. 86, no. 4, pp. 1188-1192, 1989.

[36] S. A. Elg, L. F. Carson, J. M. Fowler, L. B. Twiggs, M. M. Moradi, and S. Ramakrishnan, "Ascites levels of haptoglobin in patients with ovarian cancer," Cancer, vol. 71, no. 12, pp. 3938-3941, 1993.

[37] S. R. Harvey, S. K. Nayak, G. Markus et al., "Cancer cells release a covalent complex containing disulfide-linked domains from urinary plasminogen activator, neural cell adhesion molecule, and haptoglobin and $\beta$ chains," Archives of Biochemistry and Biophysics, vol. 345, no. 2, pp. 289-298, 1997.

[38] E. Miyoshi and M. Nakano, "Fucosylated haptoglobin is a novel marker for pancreatic cancer: detailed analyses of oligosaccharide structures," Proteomics, vol. 8, no. 16, pp. 3257-3262, 2008.

[39] U. M. Abd Hamid, L. Royle, R. Saldova et al., "A strategy to reveal potential glycan markers from serum glycoproteins associated with breast cancer progression," Glycobiology, vol. 18, no. 12, pp. 1105-1118, 2008.

[40] R. P. Beckmann, L. A. Mizzen, and W. J. Welch, "Interaction of Hsp 70 with newly synthesized proteins: implications for protein folding and assembly," Science, vol. 248, no. 4957, pp. $850-854,1990$. 
[41] J. E. Rothman and S. L. Schmid, "Enzymatic recycling of clathrin from coated vesicles," Cell, vol. 46, no. 1, pp. 5-9, 1986.

[42] B. K. Shin, H. Wang, A. M. Yim et al., "Global profiling of the cell surface proteome of cancer cells uncovers an abundance of proteins with chaperone function," The Journal of Biological Chemistry, vol. 278, no. 9, pp. 7607-7616, 2003.

[43] Y. Evdokimovskaya, Y. Skarga, V. Vrublevskaya, and O. Morenkov, "Secretion of the heat shock proteins HSP70 and HSC70 by baby hamster kidney (BHK-21) cells," Cell Biology International, vol. 34, no. 10, pp. 985-990, 2010.

[44] P. Nirdé, D. Derocq, M. Maynadier et al., "Heat shock cognate 70 protein secretion as a new growth arrest signal for cancer cells," Oncogene, vol. 29, no. 1, pp. 117-127, 2010.

[45] H. Sage, R. B. Vernon, S. E. Funk, E. A. Everitt, and J. Angello, "SPARC, a secreted protein associated with cellular proliferation, inhibits cell spreading in vitro and exhibits $\mathrm{Ca}+2$ dependent binding to the extracellular matrix," The Journal of Cell Biology, vol. 109, no. 1, pp. 341-356, 1989.

[46] N. Said, I. Najwer, and K. Motamed, "Secreted protein acidic and rich in cysteine (SPARC) inhibits integrin-mediated adhesion and growth factor-dependent survival signaling in ovarian cancer," The American Journal of Pathology, vol. 170, no. 3, pp. 1054-1063, 2007.

[47] M. A. Nagai, R. Gerhard, J. H. T. G. Fregnani et al., "Prognostic value of NDRG1 and SPARC protein expression in breast cancer patients," Breast Cancer Research and Treatment, vol. 126, no. 1, pp. 1-14, 2011.

[48] R.-L. Xie and G. L. Long, "Role of N-linked glycosylation in human osteonectin. Effect of carbohydrate removal by $\mathrm{N}$-glycanase and site-directed mutagenesis on structure and binding of type V collagen," The Journal of Biological Chemistry, vol. 270, no. 39, pp. 23212-23217, 1995.

[49] K. Mills, P. B. Mills, P. T. Clayton, N. Mian, A. W. Johnson, and B. G. Winchester, "The underglycosylation of plasma $\alpha_{1}$ antitrypsin in congenital disorders of glycosylation type I is not random," Glycobiology, vol. 13, no. 2, pp. 73-85, 2003. 


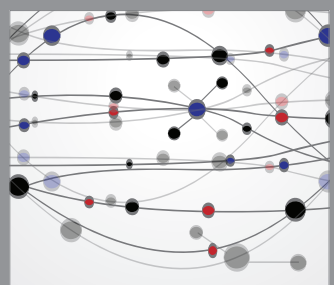

The Scientific World Journal
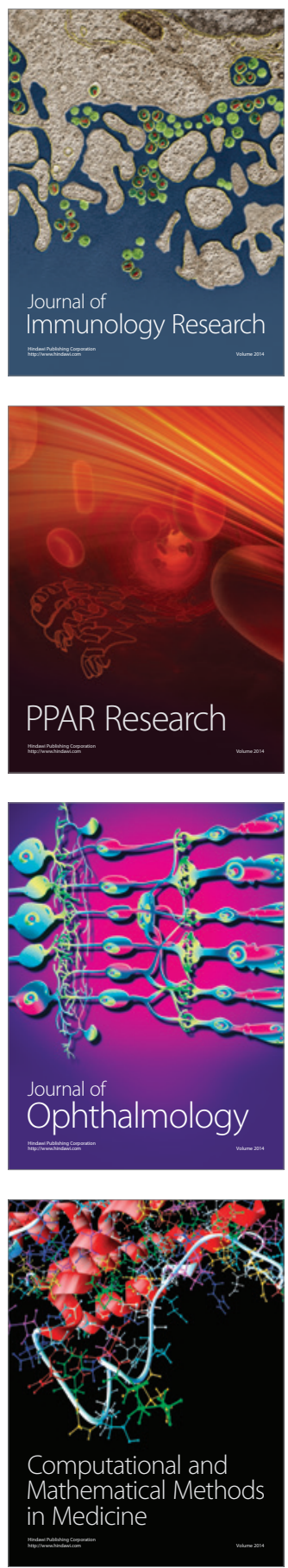

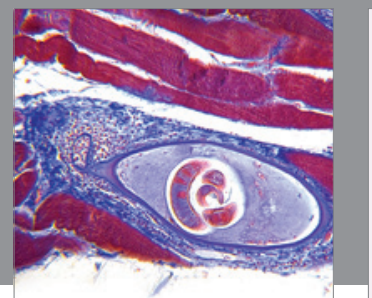

Gastroenterology

Research and Practice
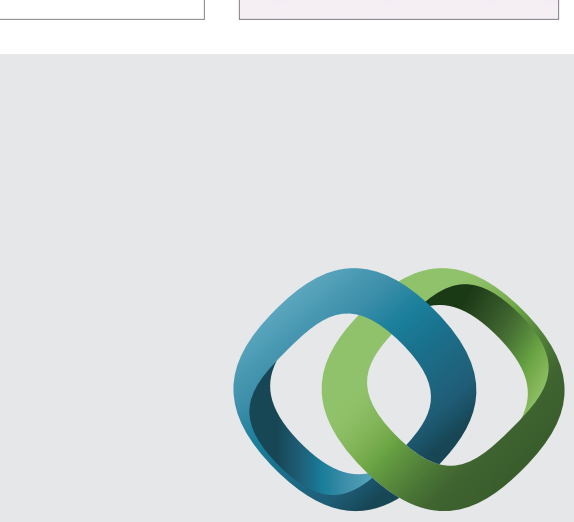

\section{Hindawi}

Submit your manuscripts at

http://www.hindawi.com
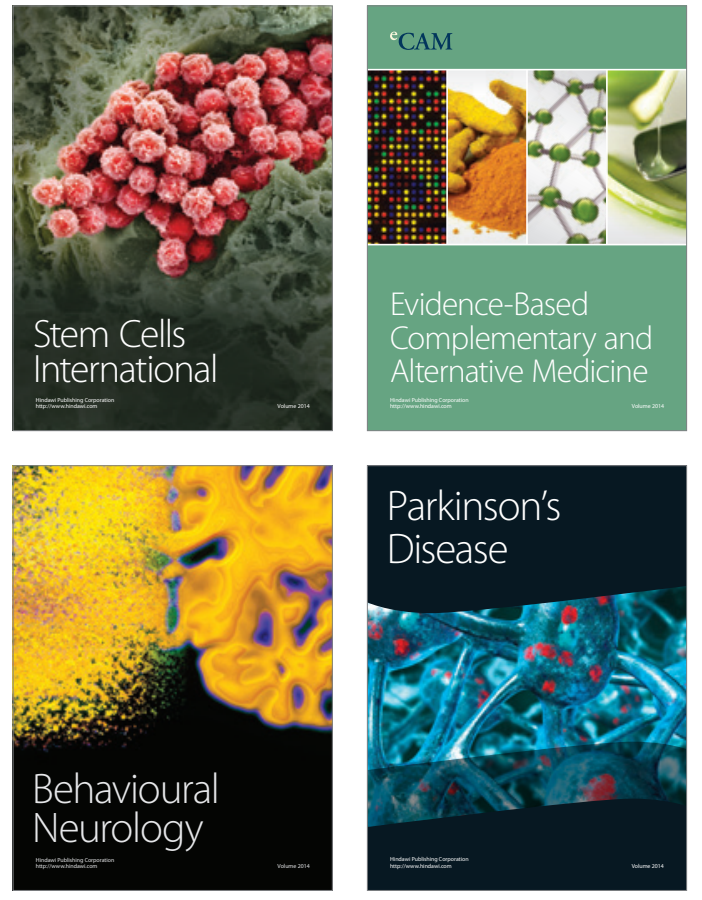
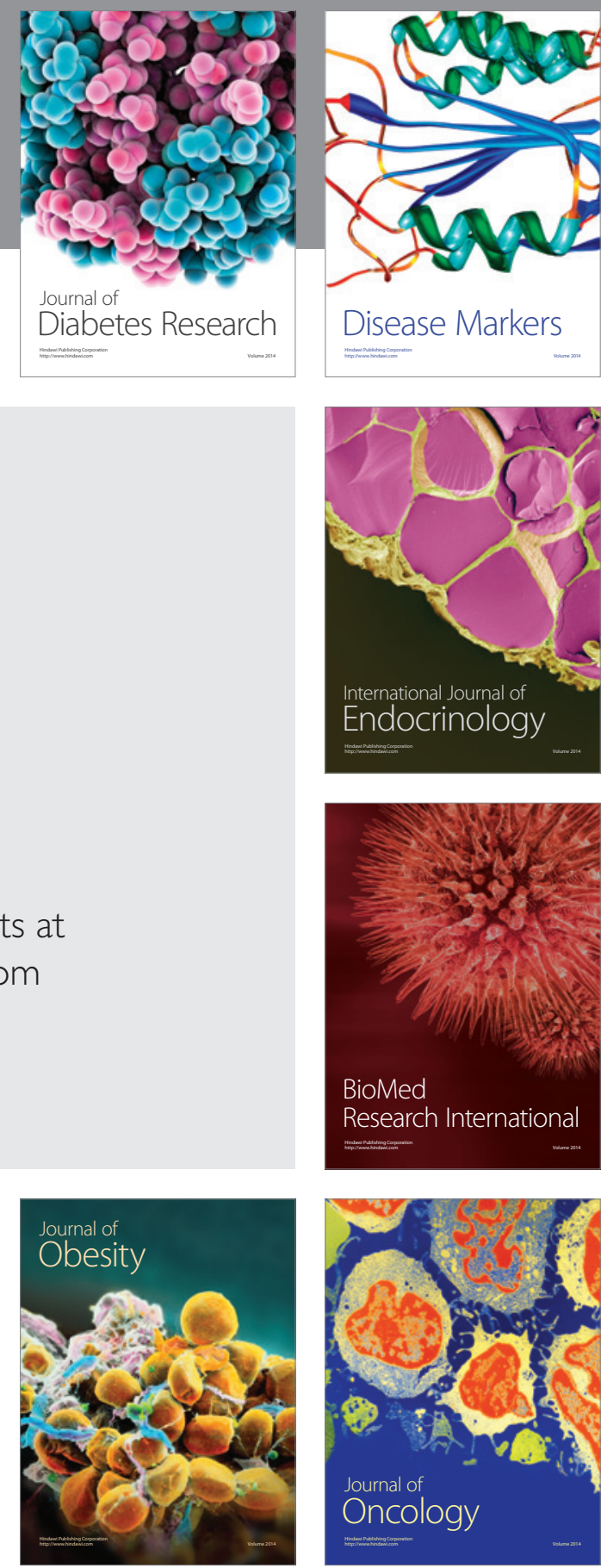

Disease Markers
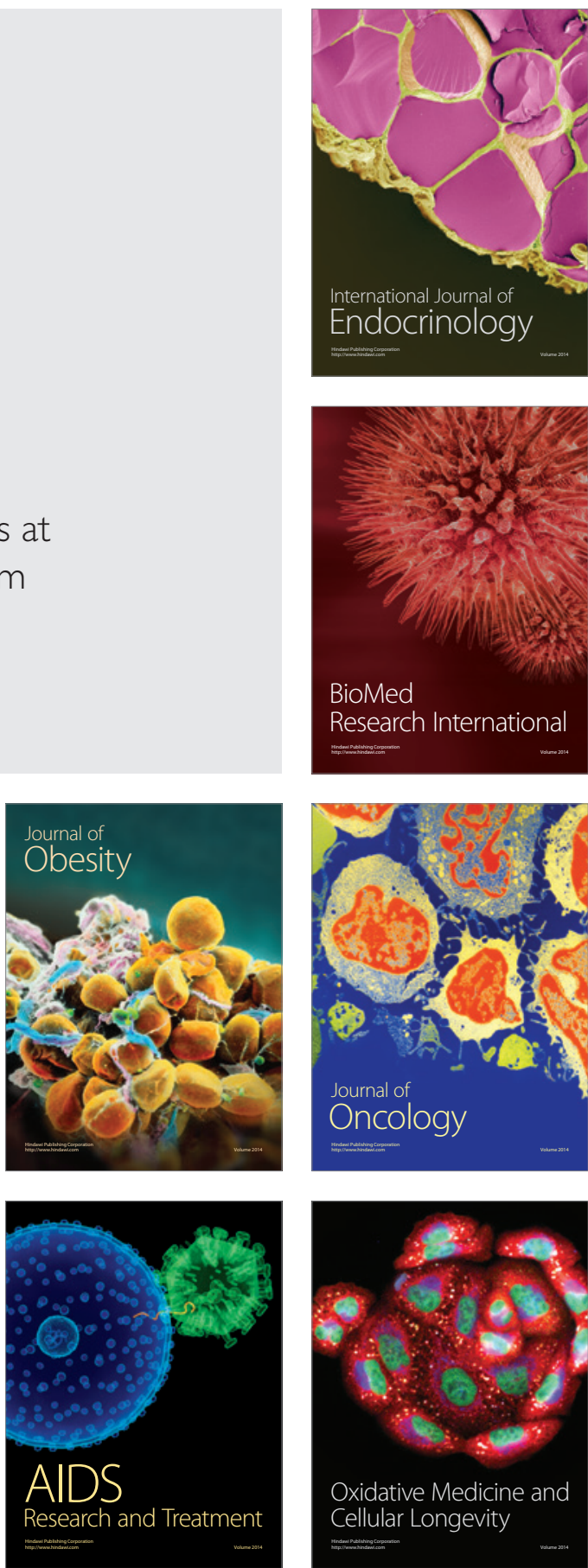